Stroke units

\section{When is a stroke unit not a stroke unit?}

\section{K M McPherson, H K McNaughton}

\section{We need to do better than just naming services}

ए vidence that stroke units save lives and reduce disability is now accepted. In some countries, including the United Kingdom, these findings have contributed to a government directive for all hospitals dealing with stroke to have had a dedicated stroke unit by April 2004. ${ }^{1}$ Despite the welcome strength of such political mandates, a number of crucial factors must be addressed if a real life stroke unit is to accomplish what research has shown to be possible. The most recent report on the National Sentinel Stroke Audit in this issue of QSHC raises some vital issues, ${ }^{2}$ not just for the UK where the number of hospitals with "stroke units" is relatively impressive $(73 \%$ and counting as of February 2002), but also for other countries where there may be few, if any, units. If we fail explicitly to respond to these important findings, we should not be surprised when we fail to achieve outcomes we know to be possible.

\section{WHAT'S IN A NAME?}

We could be forgiven for thinking that what one person calls a stroke unit might be similar to that of anotherbut, no. Rudd and colleagues ${ }^{2}$ highlight the great variability in what is actually provided-despite commonality in name and, no doubt, a shared purpose in trying to improve services for people with stroke. Less than half of those hospitals which stated they had dedicated units reported having all five of the features shown to be required for the significant improvement in survival and reductions in morbidity (see table 1 in Rudd et $\mathrm{al}^{2}$ ). ${ }^{3}$ Indeed, some "units" had only one characteristic. This apparent misnaming is of concern, given that it is, of course, the characteristics of the unit and not its label that makes the difference for patients and their families.

Even if you have a stroke unit, how can its existence provide benefit for patients with a stroke who spend no time there? Rudd et al found that just over one third of those patients admitted to hospitals with a stroke unit actually spent any time on it. It's a little hard to see how patients could accrue benefit simply by being "near" one, and a recent randomised controlled trial has indeed shown that a dedicated stroke unit was superior to a mobile stroke team. ${ }^{4}$ As such, stroke units are clearly the gold standard of care for all people with stroke, and they must have the capacity to address the needs of the population to be served.

Of interest, the characteristic that ranks as second on the list of five after "staff with a specialist interest in stroke or rehabilitation" is "routine involvement of carers in the rehabilitation process". ${ }^{3}$ One might therefore reasonably expect that involvement of carers would be the second most achieved item in the audit. But, no-this is not the case. While the authors caution that this characteristic was not measured directly but based on the presence or absence of links with associated organisations, the findings are disappointing. Almost without exception, only those units with all five characteristics noted such a relationship. The question that must exist for the other 56\% (and possibly even the "best" $46 \%$, given the indirect measure) is whether the involvement of carers is at a level proposed to be key to success.

\section{WHY THE MISMATCH BETWEEN NAME AND ACTUALITY?}

The difference is perhaps unsurprising, given pressures to meet government directives and the sanctions for not doing so. In the face of "opportunity costs" and a lack of dedicated funding, pragmatic adaptation at a local level is probably inevitable, albeit regrettable. We have a long way to go before we know which specific characteristics of a "stroke unit" are fundamental to outcome ${ }^{5}$ - that all-important question that audits just can't answer. It is paramount that we determine the relative contribution of each of the five identified features, and possibly others yet to be determined, if services are to live up to their potential.

The bottom line is that we know that, after stroke, people experience tangible benefits from the care and management offered by dedicated stroke units. The New Zealand stroke guidelines recently set a key performance indicator "that $>95 \%$ of all people with stroke admitted to hospital spend $>50 \%$ of their time in hospital in a stroke unit". ${ }^{6}$ Of course, to meet this standard, hospitals have to have a stroke unit and ensure sufficient capacity in it, something we cannot claim to have as yet in New Zealand. Secondly, until we know differently, we must ensure that all stroke units operate using the five fundamental characteristics described by Rudd and colleagues. Finally, if we want improved processes and outcomes in stroke care, we have to ensure the structures (sufficient resources, staffing and capacity) are fit for the purpose. Demanding more of services without such structural change is likely to be both futile and frustrating. ${ }^{7}$ What we do know is that simply giving something a name is not enough. The paper by Rudd et al is a salutatory reminder of this.

Qual Saf Health Care 2005; 14:6.

doi: 10.1136/qshc.2004.013201

\section{Authors' affiliations}

K M McPherson, National Institute for Rehabilitation Research, Division of Rehabilitation and Occupation Studies, Auckland University of Technology, Auckland, New Zealand

H K McNaughton, Medical Research Institute of New Zealand

Correspondence to: K McPherson, $\mathrm{PhD}$, Professor of Rehabilitation (Laura Ferguson Chair), National Institute for Rehabilitation Research, Division of

Rehabilitation and Occupation Studies, Auckland University of Technology, Private Bag 92006, Auckland, New Zealand; kathryn. mcpherson@aut.ac.nz

\section{REFERENCES}

1 Department of Health. The national service framework for older people. London: Department of Health, 2001

2 Rudd AG, Hoffman A, Irwin P, et al. Stroke units: research and reality. Results from the National Sentinel Audit of Stroke. Qual Saf Health Care 2005; 14:7-12

3 Stroke Unit Trialists' Collaboration. Organised inpatient (stroke unit) care for stroke (Cochrane Review). In:The Cochrane Library.Issue 4. Oxford: Update Software, 2002.

4 Evans A, Perez I, Harraf F, et al. Can differences in management processes explain different outcomes between stroke unit and stroke-team care? Lancet 2001;358:1586-92.

5 McNaughton HK, McPherson KM, Taylor WJ, et al. The relationship between process and outcome in stroke care. Stroke 2002;34:713-7.

6 Baskett J, McNaughton $\mathrm{H}$, eds. Life after stroke New Zealand stroke guideline, 2nd ed. Wellington: Stroke Foundation of New Zealand 2003 (available online at, www.stroke.org.nz).

$7 \mathrm{McNaughton} \mathbf{H}$. Doctors playing at politics. BMJ 2004;329:925. 